\title{
HOSPITALIDADE E RELIGIÃO NÓMADA: IDENTIDADE PARA ALÉM DA VIOLÊNCIA
}

\author{
Hospitality and Nomadic Religion: Identity over and Above Violence
}

João Manuel Duque *

RESUMO: Partindo de uma noção fechada de identidade, seja pela sua redução territorial seja pela sua redução cultural ou mesmo individual, que poderia encontrar apoio numa concepção de religião como posse exclusiva da referência a um único Deus verdadeiro ou como processo sacrificial, chegar-se-á a uma relação inevitável entre religião e violência. Propõe-se aqui um outro princípio, inspirado em Paul Ricoeur, Jacques Derrida, Jan Patocka e Emmanuel Levinas, que explora a dimensão excessiva e gratuita do religioso, interpretado como responsabilidade e com aplicação concreta no dinamismo da hospitalidade incondicional. Isso origina identidades religiosas nómadas, as quais estariam, em princípio, imunes à possibilidade de violência, a não ser que se trate de uma "violência" contra a violência, por exigência identitária

PALAVRAS-CHAVE: Religião. Violência. Hospitalidade. Responsabilidade. Ética.

ABSTRACT: A strict notion of identity, defined either by its territoriality or by its cultural or individualistic reduction, can find support in a conception of religion whose sole reference is to a single true God or to a sacrificial process, leading to an inevitable relationship between religion and violence. In this paper, however, another principle, inspired by Paul Ricoeur, Jacques Derrida, Jan Patocka and Emmanuel Levinas, has been adopted. It explores the excessive and gratuitous nature of the religious, interpreted as responsibility and concretely applicable to the dynamics of unconditional hospitality. Such an approach gives rise to nomadic religious identities that, in principle, should be immune to the possibility of violence, unless it is, for reasons of identity, a "violence" against violence.

KEYWORDS: Religion. Violence. Hospitality. Responsibility. Ethics.

* Universidade Católica Portuguesa, Braga, Portugal. 


\section{Introdução}

$\mathrm{O}$ circuito entre religião, identidade e violência parece instaurar um círculo vicioso omnipresente e inevitável. E de facto, na história da Humanidade, até à atualidade, os processos exacerbados de autoidentificação tem-se servido, muitas vezes, da dimensão religiosa, nomeadamente para intensificar o seu potencial violento, demonizando o outro em nome do endeusamento do mesmo, que acaba por substituir ou fazer-se equivaler ao próprio "nome" de Deus. A factualidade histórica deste esquema, contudo, pode não justificar a sua inevitabilidade fundamental. Não será possível pensar o religioso de outro modo, precisamente como fundamento e impulso para a superação do inquestionável fato de certa tendência humana para a violência?

No sentido de tentar responder positivamente a esta questão - e essa será a tese escondida nas linhas que se seguem - propõem-se aqui os seguintes passos: em primeiro lugar, colocaremos em questão o conceito de sagrado, devido às suas ambiguidades; depois, precisamente como alternativa, apresentar-se-á o que se poderia denominar o princípio da responsabilidade, enquanto articulação da santidade como superação da sacralidade; nesse contexto hermenêutico, far-se-á uma aproximação ao que possa significar a referência a Deus, como núcleo do religioso; por último, propõe-se uma conceção "nómada" do religioso - nomeadamente da experiência bíblica da fé - baseada na categoria da hospitalidade, que supera as reduções da identidade a processos violentos de afirmação da mesmidade.

\section{Ambiguidades do "sagrado"}

Uma primeira abordagem ao fenómeno religioso poder-nos-ia conduzir à sua compreensão como sujeição do humano ao "sagrado". Seja pelo temor seja pelo fascínio, os humanos sentir-se-iam de tal modo afetados por uma dimensão ou uma realidade de tal maneira indomável, que se limitariam a aceitar uma inevitável sujeição a esse tremendum et fascinosum originário, que parece comandar as suas existências. Uma das suas manifestações primordiais seria o próprio destino, implacável fado que tudo determina e do qual os humanos não seriam senão o efeito trágico.

Mas a sua presença dominadora pode manifestar-se também na atuação de outras forças, naturais ou culturais, exteriores ou interiores a cada um, as quais representam uma dimensão demoníaca que domina os humanos e que eles não podem dominar, mesmo que o tentem através de vários processos, nomeadamente rituais ou sacrificiais. Assistimos, neste nível, a uma espécie de violência do sagrado sobre os humanos, como violência ontológica originária, anterior e independentemente da liberdade e de 
qualquer iniciativa pessoal ou grupal. Assumido o religioso como a própria dimensão desta violência originária, a sua aplicação concreta, nomeadamente cultural e política, resulta em inevitável e trágica transferência dessa violência para as relações do sujeito ou do grupo com o outro diferente de si, precisamente como aplicação da referência ao sagrado violento originário.

O reverso da medalha desta subjugação ao sagrado como demoníaco é, normalmente, a pretensão de propriedade sobre o sagrado. Dessa posse é que resultaria a afirmação de uma identidade por oposição a uma alteridade. Aquele ou aqueles que possuem acesso a uma experiência do sagrado, mesmo como demoníaco, consideram-se idênticos por serem eleitos e possuírem um privilégio que os distingue de todos os outros, encontrando aí precisamente a sua identidade. Os outros diferentes surgem como ameaça a essa identidade, tanto mais quanto afirmam também a sua pretensão à posse do sagrado, ainda que de outro modo. De uma forma algo complexa e subtil, o outro passa a ser demonizado e, estranhamente, identificado com o sagrado que subjuga e domina - e provoca medo, mesmo que também possa provocar fascínio. Nesse emaranhado mecanismo psicossocial, a identidade, apoiada no religioso, passa a originar uma forte confinação do mesmo à sua mesmidade e, inevitavelmente, uma agressiva exclusão do outro, pretensamente como único modo de afirmação da identidade própria. A relação violenta entre os diferentes parece assim inevitável. A identidade - pessoal, cultural e também religiosa - surge, desse modo, como limitação e exclusão, seja na dimensão territorial, seja na dimensão étnica, seja mesmo na dimensão ideológica.

Mas a violência pode surgir não apenas da ameaça do outro sobre o mesmo pelo facto de ser diferente, mas também do facto de o outro constituir, de algum modo, um rival no acesso à posse do sagrado - ou ao seu favor. É a isso que, no seu sentido mais genérico, René Girard chama o "desejo mimético" (GIRARD, 1972, 1992, 2011), que pode ser compreendido, de forma exemplar, na narrativa de Gn 4, relativa ao episódio entre Caim e Abel. De facto, os dois irmãos lutam pela posse do mesmo sagrado que é, segundo eles, o agrado ou o favor do pai (representado, no caso, por Deus). Trata-se, de facto, de um arquétipo psíquico corrente, verificável frequentemente na relação entre irmãos, sobretudo na infância. Por isso, esta narrativa pode ser tomada, sobretudo, como representação mítica da origem da própria violência inter-humana. Só por isso, já se encontra no âmbito de certa dimensão religiosa, uma vez que esse âmbito nos conduz à dimensão mais originária daquilo que somos.

Girard, para além disso, situa a dimensão explicitamente religiosa do problema na forma como dele deriva a organização das comunidades humanas. O desejo mimético conduziria à violência indiferenciada de todos contra todos, já que todos são filhos do mesmo pai e todos o desejam exclusivamente para si. Para sair dessa indiferenciação mortal, será 
necessário organizar a violência e, por essa via, organizar a vida social. Isso acontece pelo sacrifício de uma vítima, que funciona como bode expiatório do potencial de violência total. Sobre essa vítima, que depois é representada ritualmente no sacrifício religioso, funda-se a possibilidade da convivência humana. A superação da violência mortal exigiria, por isso, um outro tipo de violência, precisamente a violência do religioso, no sentido que lhe é dado por Girard. O princípio da violência, como origem, parece portanto incontornável.

Mas é possível encontrar, na mesma narrativa, a formulação de um outro princípio, o qual poderá não apenas controlar a violência provocada pelos mecanismos do desejo mimético, mas superá-la completamente, fazendo assentar a identidade dos sujeitos e das sociedades, e a respetiva dimensão religiosa, precisamente numa outra fonte, que não a da violência sacrificial. Esse outro princípio seria o princípio da responsabilidade pelo outro.

É com base nesse outro princípio que se funda uma humanidade alternativa, representada na eleição de um Povo, o Povo de Israel - no caso da narrativa referida, fundado não sobre Caim e sobre o sacrifício vitimatório sacralizado, mas sobre Set, filho de um outro início, que substitui (e eventualmente reabilita) a vítima, dando-lhe futuro. Esse outro início aponta para uma convivência possível, em que a relação ao outro não origina violência, mas a supera.

Para formular e fundamentar esta proposta de leitura, propõe-se aqui como ponto de partida o que poderia considerar-se o centro do texto, precisamente a pergunta de Deus: "Onde está o teu irmão Abel?" (Gn 4, 9). Esta pergunta, em rigor, não deveria ser interpretada como juízo, em ordem a uma eventual pena. Nesse caso, a pergunta mais adequada seria: "O que fizeste ao teu irmão?" Mas essa pergunta só vem depois, porque verdadeiramente já é segunda, em relação à pergunta primordial. A resposta de Caim, pela negativa, leva a pensar numa outra interpretação da pergunta original: "Sou porventura guarda do meu irmão?" Precisamente, é isso que o novo princípio exige de um irmão, ou seja, de qualquer humano em relação ao outro. Caim não entende esse princípio e, por isso, sucumbe à violência.

Estaremos perante a revelação, neste condensado textual, de um imperativo que precisamente constituirá a identidade humana. E esse imperativo originário da identidade humana é o imperativo da responsabilidade pelo outro. Antes de tudo, é um imperativo pessoal, dirigido a cada um. Emmanuel Lévinas, que exprimiu esta hermenêutica alternativa como ninguém, refere-se-lhe do seguinte modo: "No dizer da responsabilidade - que é exposição a uma obrigação em que ninguém me poderá substituir - sou único. A paz com o outro é, antes de tudo, tarefa minha. A não-indiferença - o dizer - a responsabilidade - a aproximação - é a realização do único responsável - de mim... Eu coloco-me na passividade de uma convocação indeclinável - em acusativo - si" (LEVINAS, 1974, p. 217). 
A identidade pessoal deixa de estar assim relacionada primordialmente com a substância individual de cada um ou com o impulso de afirmação de si, seja no instinto de sobrevivência, seja no instinto de vitória num conflito insanável de concorrência. Nas palavras de Lévinas, esta outra matriz da identidade pessoal considera o sujeito "como se o eu, enquanto responsável de outro, tivesse um passado imemorial, como se o Bem fosse antes do ser, antes da presença" (LEVINAS, 1993, p. 207).

Assim, a violência pretensamente originária - nomeadamente a violência baseada no desejo mimético, que especialmente afeta os semelhantes, nomeadamente os crentes das diversas religiões, que habitualmente se denominam irmãos - é superada, na medida em que é proposta uma origem mais originária. $\mathrm{O}$ estatuto originário da violência seria assim substituído pelo estatuto originário da responsabilidade. Esta seria, ou propriamente não-sacrificial - na medida em que não implica o sacrifício violento do outro como condição da identidade pessoal ou coletiva - ou então representativa de um outro modo de sacrifício - o sacrifício de si mesmo e da pretensão absoluta do desejo próprio, para encontrar a identidade na dádiva de si, como refém do outro, até à substituição. Ainda nas palavras de Lévinas, "a eleição do eu, a sua própria ipseidade, revela-se como privilégio e subordinação - porque não o põe entre os outros eleitos, mas precisamente em frente deles, para os servir, e porque ninguém se pode substituir a ele para medir a extensão das suas responsabilidades" (LEVINAS, 1971, p. 238). Manifesta-se assim um outro tipo de violência pacificadora, que é a que resulta da sujeição de mim ao outro, em liberdade finita. "A relação ética não é revelação de um dado, mas exposição de mim ao outro... Aqui, há uma espécie de violência sofrida: um traumatismo no coração de mim mesmo, uma reivindicação deste Mesmo pelo Outro..." (LEVINAS, 1974, p. 219).

Para exprimir a distinção entre este princípio e o princípio da violência, presente numa outra leitura das origens, Levinas recorre à distinção entre o Sagrado e o Santo (LEVINAS, 1977). Por seu turno, o filósofo checo Jan Patocka situa aqui, precisamente, a sua definição do religioso, compreendendo-o como responsabilidade, por oposição ao pré-religioso, considerado como sacralidade demoníaca ${ }^{1}$.

\footnotetext{
${ }^{1}$ Sobre a distinção entre o Sagrado e o Religioso, ou entre o pré-histórico e o histórico, ver Patocka, 1999, p. 162: “La religion n'est pas le sacré, elle ne tire pas son origine directement de l'expérience des cérémonies et des orgies sacrés. Elle émerge là où l'on dépasse expressément le sacré en tant que démonie. Les expériences du sacré deviennent expériences religieuses dès lors qu'on tente l'intégrer la responsabilité dans le sacré ou d'assujettir le sacré à des règles dictées par la responsabilité". Cf.: Ricoeur, 1991, p. 89. Essa é também a proposta de Jacques Derrida, inspirada explicitamente em Patocka; Cf.: Derrida, 1999, p. 16-17: "Il y a religion, au sens propre du mot, à partir de l'instant où le secret du sacré, le mystère orgiaque ou démonique seraient sinon détruits, du moins dominés, intégrés et enfin assujettis à la sphère de la responsabilité. Le sujet de la responsabilité serait le sujet qui a pu s'assujettir le mystère orgiaque ou démonique... La religion est responsabilité ou elle n'est pas. Son histoire n'a de sens que dans un passage à la responsabilité".
} 
Esse sagrado demoníaco pode ainda manifestar-se de outra forma, a qual pode ser identificada de igual modo no episódio de Gn 4. Sem forçar demasiado o texto e sem recusar outras interpretações, nomeadamente aquela que opõe o modelo de atividade assente na pastorícia ao modelo agrícola, nessa diferença entre Caim e Abel pode ver-se uma representação simbólica da relação entre técnica e cuidado. O pastor exerce a sua atividade cuidando do rebanho e respeitando os processos da natureza; o agricultor introduz o elemento da técnica, para dominar a natureza. É claro que, por um lado, é no recurso à técnica que o humano revela a sua humanidade, na medida em que supera a natureza e exerce o reino da liberdade. Mas também é verdade que o uso da técnica abre possibilidades de violência sobre a terra, sobre os animais, mesmo sobre os outros humanos, que poderão vir a configurar-se como uma forma de sacralidade pretensamente religiosa.

Mais uma vez, o princípio da responsabilidade exige a superação radical desta atitude violenta de domínio. Mas exige, de certo modo, o sacrifício de si - o que, aliás, se virá a revelar de forma mais clara no sacrifício de Jesus. Encontrar o fundamento da sua subjetividade e da sua liberdade o que significa encontrar o Santo, que dá sentido à existência, enquanto dimensão religiosa - precisamente na responsabilidade pelo outro, até à dádiva da vida, não deixa de ser uma manifestação da violência. Poderíamos, neste caso, considerar que a responsabilidade como religião equivale à afirmação da "violência" da responsabilidade contra e para além da irresponsabilidade da violência sacral ou demoníaca, assumida como uma força que domina o humano, exercendo violência sobre ele, e levando-o à violência sobre os outros.

\section{0 excesso do terceiro}

No episódio bíblico referido, não se apresentam propriamente os atos de responsabilidade de um irmão pelo outro - aliás, nem sequer a resposta dessa responsabilidade é apresentada. O que surge é apenas a questão, colocada por Deus: “Onde está o teu irmão?". Questão que é corretamente interpretada por Caim como interpelação à responsabilidade: "Sou porventura guarda do meu irmão?", mesmo que não a assuma como constituição de uma identidade humana para além - ou anterior - da violência.

O que se revela, aqui, é a possibilidade de uma "hermenêutica" fundamental do religioso, que neste caso coincide com os processos de originação de identidade pessoal, assente na resposta livre. A religião da responsabilidade - ou mesmo a religião como responsabilidade - interpreta-se como correspondência, enquanto respondência a um apelo originário. Esse apelo originário, em realidade, não pertence diretamente ao mundo dos fenóme- 
nos. Torna-se fenómeno apenas na mediação da resposta (CHRÉTIEN, 1992, p. 42; MARION, 1997, p. 460). Mas esta é resposta - e não o ponto de partida - precisamente porque é "religiosa", porque se religa a uma dimensão anterior, ainda que não dada diretamente como fenómeno. $\mathrm{Na}$ relação de um ao outro - do irmão ao irmão - a interpelação à responsabilidade surge assim como uma terceira dimensão - ou uma "terceira pessoa" - que origina o apelo e a exigência à responsabilidade, apelo e exigência que se tornam fenómeno na presença do outro e na resposta responsável dada ao/pelo outro.

Por não ser fenómeno - pelo menos segundo a modalidade habitual dos fenómenos imanentes ao mundo, determinados pelo espaço e pelo tempo - o terceiro que origina a responsabilidade é da ordem do excesso. Este excesso pode ser interpretado apenas como índice de negatividade, ou seja, como insinuação, através de um processo a que Levinas chama "rasto" (trace) (LEVINAS, 1972, p. 83) - e que em Derrida poderá significar o núcleo da própria desconstrução - segundo o qual não é possível absorver a alteridade na mesmidade, porque o terceiro "infinito" e sempre "ausen$t^{\prime \prime}$, ao investir a alteridade de uma dimensão excessiva, não o permite (DERRIDA, 1967, p. 104).

Esta leitura apofática da referência ao "terceiro" - que pode até ser relacionada com a tradição da teologia negativa e de certas correntes místicas - permite, de facto, contrariar a noção de religioso como posse do sagrado em conflito com outras pretensões de posse. O fundamento divino do religioso é precisamente o que fundamenta e exige a impossibilidade de qualquer pretensão de posse, seja sobre o próprio divino, seja sobre tudo aquilo que se situa no seu "rasto". Contudo, esta leitura negativa desconstrutiva - parece não permitir (ou pelo menos parece dificultar) a instauração de uma atitude positiva em relação ao fundamento do religioso ou em relação ao sujeito ou à comunidade por ele fundamentada. O que, aliás, pode correr o risco de reconduzir, de novo, a uma compreensão demoníaca dessa impossibilidade, se passar a significar, simplesmente, uma absoluta indisponibilidade do outro e da origem, sobretudo se essa indisponibilidade for interpretada como tremendum et fascinans, devido ao seu poder praticamente mágico².

\footnotetext{
${ }^{2}$ Este paradoxo do regresso do sagrado demoníaco como indisponibilidade mágica, provocado pelas diversas tentativas de domínio do real, nomeadamente através da técnica, é explorado de forma muito sugestiva por Rosa, 2019, p. 124.130: “Em muitos aspetos, o mundo da vida da modernidade tardia torna-se cada vez mais indisponível, incompreensível e inseguro. Isso leva a que, em muitos âmbitos da vida, regresse a indisponibilidade pragmática, contudo em formas transformadas e que provocam mais medo, quase como se tivéssemos criado um monstro... Uma indisponibilidade resultante de processos que procuram tornar tudo disponível origina alienação radical".
} 
O filósofo alemão Jörg Splett acrescenta um elemento importante ao fenómeno da referência ao "terceiro", na relação inter-humana ou na relação do humano ao mundo (SPLETT, 1996, p. 108). Reconhecendo a importância da posição de Levinas, através do conceito de "Illeité" (CASPAR, 2009, p. 33), explora, na relação à terceira pessoa, a dimensão da exigência ética - que, aliás, não está ausente do pensamento de Levinas, como é sobejamente sabido. Assim, o "terceiro" transcendente à pura relação binária não significa apenas a impossibilidade de posse - ou a própria impossibilidade enquanto tal, na sequência de Derrida - mas também a possibilidade e mesmo a irrupção de uma exigência positiva, que orienta para a segunda pessoa. Exigência que conduz, sempre, ao princípio da responsabilidade. $E u$, perante $t i$, sou interpelado por ele, ao respeito e à responsabilidade por ti. Aplicado este "esquema" ético ternário à dimensão religiosa, diríamos que é precisamente a sua origem transcendente e excessiva que fundamenta a relação ao diferente, como relação não apenas de respeito, mas sobretudo de responsabilidade - o que parece coincidir com a noção de religião como responsabilidade, proposta por Patocka.

Paul Ricoeur, por seu turno e embora admita uma possível ligação entre esta noção de excesso com uma atitude violenta, sobretudo originada pelo medo em relação ao sagrado, propõe uma outra leitura, muito próxima à de Splett. Por um lado, reconhece o problema: “É pois em mim mesmo que experimento essa desproporção que existe entre a minha capacidade finita de adesão e o reconhecimento de algo fundamental que sempre me excede e, pelo seu excesso, me ameaça, o que me faz sofrer. A violência torna-se, então, uma tentativa de proteção contra o perigo de desenraizamento, de cuja ameaça iminente surdamente me apercebo" (RICOEUR, 2000 , p. 29). E vai ainda mais longe, pois admite que esta violência, por seu turno, não se fica pela relação a Deus, enquanto violência sobre o transcendente, manipulado eventualmente em conceitos (doutrina) e, por extensão (ou ainda antes), em ritos e normas de conduta; o prolongamento direto desta atitude violenta primeira é a violência sobre os outros que se referem a Deus de modo diferente, mas segundo mesmo o mecanismo do desejo mimético. "Todas as outras comunidades históricas que se reclamam de um mesmo transcendente, mas nos termos de uma outra confissão, aparecem como rivais na luta pela apropriação do Ser, do Outro absoluto, tratado como um mesmo, a possuir com exclusão dos outros" (RICOEUR, 2000, p. 33). Lendo este mecanismo à luz da sua origem primeira, parece evidente poder-se então dizer: "O excesso de ser converte-se em ter, objeto do desejo de apropriação, projetando nas outras comunidades o mesmo gesto de apropriação-expropriação por rivalidade que se prolonga até mesmo no processo de acolhimento" (RICOEUR, 2000, p. 34).

No entanto, por outro lado e em clara crítica à posição global de René Girard, que liga a religião, originária e constantemente, com a violência, Ricoeur questiona-se pertinentemente: “Ora, porquê perceber aquilo que 
funda como uma ameaça e não como gratuidade e generosidade? É isso que ele é, fundamentalmente. Não é a projeção do nosso desejo de apropriação, sobre a própria origem da nossa convocação ao ser, que transforma em ameaça aquilo que não é senão doação, alargamento da minha capacidade de acolhimento?" (RICOEUR, 2000, p. 34).

Este originário alargamento da capacidade de acolhimento, se levado até ao infinito, como correspondência a uma origem incondicional da existência, aproxima-nos da questão da hospitalidade, enquanto fundamento de uma atitude incondicional, ou seja, enquanto eventual fundamento religioso da existência - ou enquanto mais correta interpretação da dimensão religiosa.

\section{Hospitalidade e religião}

A tese de partida, aqui proposta, considera que a dimensão religiosa do sentido, entendida nos termos da relação ao excesso - tal como fica sugerido pelas posições de Derrida, Splett e Ricoeur - coincide com a dimensão da incondicionalidade, tal como se manifesta numa "meta-ética" da hospitalidade.

O filósofo alemão Hans-Dieter Bahr terá sido o primeiro a propor a compreensão da hospitalidade antropológica fundamental como base de uma meta-ética (cf. Bahr, 1994). Ainda que Bahr não lhe atribua significado explicitamente religioso, não parece de todo desadequado poder interpretar essa dimensão no sentido aqui proposto, desde que a dimensão religiosa seja entendida não no sentido da sacralidade violenta ou do desejo mimético, mas no sentido do excesso que fundamenta o acolhimento, compreendido aqui precisamente como hospitalidade fundamental.

A ideia de uma "meta-ética" da hospitalidade coincide com uma hermenêutica da realidade que não a reduz à dinâmica das relações imanentes, organizadas por normativas concretas que determinam a posição dos sujeitos, de acordo com as suas pertenças e, portanto, de acordo com identidades pré-definidas por essas pertenças que, eventualmente, podem derivar em reivindicações de propriedade tendencialmente violentas. $\mathrm{Na}$ perspetiva de uma "meta-ética", as "éticas" organizadas em sistemas de normas morais, determinadas pela pertença, acabam por condicionar uma referência incondicional anterior, precisamente aquela em que os humanos partilham uma condição fundamental comum. Essa condição fundamental comum pode ser referida simplesmente a uma dimensão antropológica partilhada, ou a uma negatividade fundamental, que proíbe qualquer tipo de propriedade - como acontece com certas interpretações da referência ao terceiro, já referidas - ou pode, por outro lado, exprimir-se numa exigência positiva (ética) de hospitalidade, anterior e para além de qualquer organi- 
zação dessa hospitalidade mesma, nomeadamente em leis que confinam a identidade à pertença, nomeadamente na dimensão territorial.

Vai ser Jacques Derrida, não sem certa inspiração em Hans-Dieter Bahr com quem teve contacto, quem irá formular mais explicitamente essa dimensão da hospitalidade, fazendo-a corresponder ao seu programa de desconstrução das organizações humanas, condicionadas pela historicidade das suas configurações (DUQUE, 2017). A meta-ética da hospitalidade refere-se a uma incondicionalidade originária que supera a confinação mesmo do estrangeiro, na medida em que este é já sempre definido por uma pertença que confina a identidade, nomeadamente a um lugar, uma língua, uma nação, etc. Isso acaba por colocar em planos diversos o estrangeiro real, como aquele que é condicionado por referências de pertença que o definem como estrangeiro, e a absoluta alteridade, para a qual o outro é independente dessas condicionantes. Mesmo a hospitalidade cosmopolita, muito presente na história da literatura e do pensamento, precisamente na medida em que é regulada por regras que pressupõem a pertença como confinamento (referidas ao estrangeiro), é fundamentalmente diferente da hospitalidade incondicional (referidas simplesmente ao outro), como manifestação de uma meta-ética anterior à própria definição do estrangeiro como estrangeiro. Essa hospitalidade originária corresponderia a uma espécie de impossibilidade fenoménica, que Derrida assume habitualmente como revelação paradoxal de uma origem pré-fenoménica dos fenómenos. Ainda que seja assumida como uma impossibilidade "positiva", a sua positividade radica precisamente nessa impossibilidade fenoménica (ZAGALO, 2006, p. 318).

Ora, essa mesma "impossibilidade" fenoménica, ainda que seja ambivalente e possa conduzir a uma negatividade pura, pode ser interpretada como expressão paradoxal do caráter incondicional da interpelação (DUQUE, 2008). Diferentemente da definição da identidade humana a partir de uma pertença condicionada política, jurídica, cultural e mesmo religiosamente, uma meta-ética da hospitalidade seria anterior e independente das definições da identidade a partir de horizontes de pertença, sejam eles de que género forem. É mesmo anterior a normas éticas particulares, já situadas, normalmente expressas na lei. De facto, ela situa-se "antes e para além das normas e das leis - das leis da hospitalidade, do dever e do direito de hospitalidade inerentes ao espaço da polis. Antes portanto, e diferentemente, da sua assimilação numa determinada comunidade... diferentemente do estrangeiro que o é portanto sempre a partir de um lugar delimitado - a partir de uma ipseidade ou de um eu próprio, de uma família, uma cidade, um Estado, um direito, uma nação, uma língua e, portanto, de uma cultura -, e que é também acolhido pelo direito de um determinado lugar, pelo direito que faz esse lugar, o recém-chegado «é» e é acolhido a partir de si próprio enquanto alteridade absoluta ou secreta. Infinita. Irredutível. Incalculável. Indecidível. E o acolhimento da sua estranheza, a abertura ao inesperado da sua vinda é, para Derrida, a ética da/como hospitalidade" (BERNARDO, 2001, p. 370.372). 
A meta-ética da hospitalidade implica uma espécie de suspensão das características que distinguem o outro do mesmo e que, habitualmente, constituem a origem da identidade pela diferença. "Na hospitalidade sem condição, o hospedeiro que recebe deveria, em princípio, receber antes mesmo de saber o que quer que seja do hóspede que ele acolhe. $\mathrm{O}$ acolhimento puro consiste não apenas em não saber ou em fazer como se não soubéssemos, mas em evitar toda a questão a respeito da identidade do outro, o seu desejo, as suas regras, a sua língua, as suas capacidades de trabalho, de inserção, de adaptação..." (DERRIDA, 1997, p. 98). Também a identidade religiosa, relacionada com a pertença confinada a determinada tradição ou comunidade religiosa - que muitas vezes é aliada a específicas configurações politico-culturais - é relativizada pela meta-ética da hospitalidade.

É nesse contexto que se pode falar de "religião nómada", para referir a dimensão excessiva do religioso em relação a todas as pretensas reduções identitárias, nomeadamente aquelas que confinam a identidade a um território ou mesmo a uma comunidade. $\mathrm{O}$ recurso à noção de nomadismo, contudo, não coincide com o sentido atribuído a esse conceito por Rosi Braidotti, que o apresenta como chave de compreensão do seu "pós-humanismo crítico" (BRAIDOTTI, 2015, p. 60ss.). Segundo a sua proposta de nomadologia (BRAIDOTTI, 2011), o sujeito crítico pós-humanista não coincide com o sujeito moderno, com uma identidade definida, a qual representa, em realidade, o homem (masculino) europeu, branco, detentor de um determinado tipo de racionalidade e considerado como centro de um mundo em que o indivíduo domina o resto da realidade. $\mathrm{O}$ sujeito nómada, pelo contrário, é marcado por identidades plurais e híbridas, que impedem mesmo a referência a uma noção unívoca de identidade. Em rigor, nem sequer se lhe pode aplicar a noção de identidade subjetiva, pois ele encontra-se no fluxo de uma realidade em movimento, da qual é simplesmente uma parte, também ela em movimento.

A inspiração para a presente proposta de "nomadismo religioso" é sobretudo bíblica. No contexto específico da questão da hospitalidade, essa referência é também salientada por Derrida, quando evoca a tradição das denominadas «cidades-refúgio». "Uma tradição na qual a polis não era, de uma certa maneira, o horizonte último das cidades que, quanto à hospitalidade, podiam elevar-se acima do Estado, constituindo-se assim como uma espécie de santuários ou de asilos. Independentemente das nações e do Estado, independentemente da legislação estatal, tais cidades podiam acolher quem desejassem. E o filósofo lembra que o texto fundador de uma tal jurisprudência, aquela que outorga às cidades um singular direito à imunidade e à hospitalidade é sobretudo Números, 35, 9-32, onde Deus ordena a Moisés a instituição de seis «cidades de refúgio» ou «de asilo» para acolher todos aqueles que eram perseguidos por uma justiça cega e vingativa, ou por crimes de que eram os autores involuntários" (Bernardo, 2002, p. 431). 
Este nomadismo corresponde, por um lado, à experiência do deserto, para a qual a pertença política, na confinação a uma polis limitada, não determina as identidades, mas sim o estatuto pessoal e relacional, realizado num permanente não-lugar e numa forma de não-pertença a um espaço fechado. Isso significa que essa experiência do deserto não implica o abandono da noção de sujeito e de identidade, num nomadismo difuso e fluído, apenas a desloca por um outro centro, precisamente o centro pessoal e ético. É na resposta à interpelação ética de responsabilidade pelo outro, seja quem for, na realização do dever de o acolher independentemente das suas características e das suas pertenças, que a identidade do sujeito se constitui como tal, como vimos nas expressões inequívocas de Levinas. No seguimento de uma antropologia (fundamentada teologicamente) de raiz hebraica, é possível relacionar a meta-ética da hospitalidade - precisamente por não ser possível reduzi-la à relação hospitaleira binária, articulada interpessoalmente na diferença entre o próprio e o estrangeiro - com a dimensão ternária evocada acima, enquanto modelo de uma identidade religiosa aberta a uma transcendência que supera a contraposição ao outro como exclusão. Em rigor, o outro como hóspede representa um caso de "impossibilidade lógica e simultaneamente de manifesta presença. O hóspede é a figura paradoxal do terceiro: em realidade não deveria existir, mas existe. Desta situação aporética resultam simultaneamente a sua incomodidade e a sua indisponibilidade" (FOUNTOULAKIS \& PREVISIC, 2011, p. 13).

A indisponibilidade não é, contudo, um conceito apenas negativo, mas refere-se a um modo de relação à realidade - humana e não-humana - que supera a pretensão de posse, que coloca tudo disponível para a utilização por parte do sujeito humano. Como vimos, Hartmut Rosa explorou de forma sugestiva a relação entre a modernidade e a vontade de disponibilização do real para utilização do sujeito (ROSA, 2018). Essa disponibilização do mundo, sobretudo através do seu controlo tecnológico, terá desembocado, contudo, numa nova indisponibilidade, que parece coincidir com uma compreensão do mundo com base na sacralidade - a qual, como vimos, acaba por originar uma relação violenta entre os humanos.

Em sentido inverso, toda a tradição bíblica - e mais especificamente o próprio cristianismo - pode ser interpretada segundo a chave da hospitalidade incondicional. De facto, a atitude crente, enquanto manifestação da mais genuína atitude religiosa, pode ser compreendida como atitude de hospitalidade (DUQUE, 2008). O ato de fé é, na sua forma primordial, um ato de hospitalidade por relação a uma alteridade originária, anterior a todo o condicionamento pessoal ou socio-histórico. A identidade do crente é, antes de tudo, determinada por essa referência originária, concretizada pelo facto de este dar "crédito àquele que está diante de si e, ao mesmo tempo, a toda a vida" (THEOB ALD, 2007, p. 62). Este crédito não está, mesmo formalmente, determinado por condições, mas manifesta ele mesmo uma completa abertura para o que vem. O seu paradigma pode 
encontrar-se na própria atitude hospitaleira de Jesus, que é permanente acolhimento do outro que vem - do Outro que o envia e do outro a quem é enviado. Essa atitude pode resumir-se numa "absoluta prioridade dada à sua presença junto do outro e uma igualmente absoluta distância em relação a si mesmo" (THEOBALD, 2007, p. 66). O outro humano que inesperadamente vem ao encontro e reclama acolhida é sempre já mediação do Deus outro, que assim permanentemente vem, para além de tudo o que já está presente. Esta liberdade, em relação a si mesmo, como condição de construção da identidade, é ao mesmo tempo a liberdade em relação à mesmidade institucional, já que as condições predeterminadas pelo grupo, pela comunidade, pelas regras ou leis, são superadas na atitude hospitaleira do crente: crer é acolher Deus, livre das condicionantes, e acolher o outro, para além de todos os enquadramentos: "A santidade «hospitaleira» do Nazareno... não exclui ninguém; ele toca um grande número dos que fazem parte do processo, como atores: quaisquer pessoas, em condições, de profissões, em situações sociais as mais diversificadas" (THEOBALD, 2007, p. 68). As obras da lei não podem determinar o ato de crer, já que este se define pela própria superação - não anulação - da lei.

No ato de crer, compreendido segundo o modelo da hospitalidade, instaura-se uma desmedida, que o identifica como excessivo em relação às possibilidades humanamente consideradas. É certo que não há possibilidade humana de crer sem mediações, segundo a carne das histórias humanas concretas, por isso mesmo condicionadas. Mas, retomando uma feliz formulação de Pierre Gisel, "se é aí onde o crer ganha necessariamente corpo, é precisamente para aí assinalar, justamente, um excesso" (GISEL, 1990, p. 9). O ato de fé cristã não seria um ato se não fosse incarnado na realidade humana condicionada; mas não seria um ato de fé cristã, se não fosse excessivo em relação às condições da sua incarnação. “Em profundidade, conjugamse por isso uma incarnação máxima e um apelo ao excesso, uma entrada na imanência e a marca de uma transcendência" (GISEL, 1990, p. 139).

Deste paradoxo entre excesso indisponível ou incondicional e articulação histórica da pertença, em identidades confinadas, parece resultar uma aporia ou mesmo uma impossibilidade que poderia, quando muito, originar uma utopia. No entanto, dada a impossibilidade da sua realização histórica, apenas serviria como ideia reguladora, do ponto de vista negativo - para interditar pretensões desmesuradas do humano. E isso já não é pouco. Mas haverá que pensar numa possibilidade mais positiva, enquanto realização possível, ainda que relativa, de uma exigência não apenas a não desejar possuir ou eliminar o outro - que assim permaneceria indiferente na sua alteridade - mas a assumir a responsabilidade por ele, como hóspede a acolher. Fundamentalmente, encontramo-nos num contexto que Ricoeur aborda frequentemente, pretendendo retirar fertilidade daquilo que parece ser aporético e por isso impossível. A tensão entre o excesso e as possíveis realizações históricas implica uma relação permanente entre o nomadismo 
incondicional da pessoa humana e a sua incarnação em pertenças inevitavelmente confinadas: "A incorporação tenaz, passo a passo, de um grau suplementar de compaixão e de generosidade nos nossos códigos - código penal e código de justiça social - constitui uma tarefa perfeitamente razoável, se bem que difícil e interminável" (RICOEUR, 1990, p. 66). O que se aplica aos códigos jurídicos e culturais, poder-se-ia transferir também para os códigos das identidades religiosas.

\section{Conclusão}

Após este percurso, regressemos à questão da relação entre religião e violência. Ela é, de facto, ambivalente. Por um lado, o potencial de violência das relações inter-humanas, assente nas afirmações identitárias por exclusão do outro, parece ganhar um fundamento originário, diríamos que ontológico, quando referido à dimensão religiosa, precisamente por aí se pretender efetuar uma experiência do sentido originário de tudo. Assim sendo, a dimensão religiosa parece confirmar uma ontologia e uma antropologia fundadas na violência.

No entanto, é possível chegar à conclusão contrária, precisamente através de uma outra interpretação, seja da dimensão religiosa - assente agora na categoria do excesso e do dom - seja da antropologia, agora baseada não no desejo mimético mas no princípio da responsabilidade pelo outro. Uma e outra, contudo, não podem pensar-se separadamente, já que o princípio da responsabilidade pelo outro implica a referência a um terceiro que interpela e, assim, fundamenta a própria relação de responsabilidade. Nessa referência ao terceiro é que podemos encontrar o lugar mais específico do religioso, seja como impossibilidade negativa, quanto às pretensões violentas de posse do outro, seja como possibilidade positiva, enquanto interpelação que funda precisamente uma religião da responsabilidade.

Pensada assim, a dimensão religiosa do humano situar-se-ia numa espécie de lugar sem lugar, numa articulação simultaneamente histórica e presente e, ao mesmo tempo, transcendente em relação a qualquer lugar e momento históricos. É essa característica que permite falar de religião nómada, ou do nomadismo como sua característica fundamentais. Isso tem implicações essenciais sobre o modo como se compreendem as diversas identidades culturais-religiosas e a sua relação. Para a religião nómada a identidade não pode afirmar-se por exclusão ou oposição ao outro, mas pelo acolhimento do outro, na sua irredutível alteridade. A hospitalidade é, por isso, o seu modelo.

Estaremos perante uma utopia? Em parte. Mas as utopias são importantes como permanente alimento do quotidiano realizável historicamente e como 
sadia relativização das realizações concretas. Nesse sentido, a religiosidade nómada subjaz às identidades religiosas concretas, adquirindo nelas um corpo histórico mas, ao mesmo tempo, impedindo que estas se afirmem violentamente contra os diferentes.

\section{Referências}

BAHR, H.-D. Die Sprache des Gastes. Eine Metaethik. Leipzig: Reclam, 1994.

BERNARDO, F. A ética da hospitalidade ou o porvir do cosmopolitismo por vir (I). Revista Filosófica de Coimbra, Coimbra, v. 10, n. 20, p. 333-426, 2001.

BERNARDO, F. A ética da hospitalidade, segundo J. Derrida, ou o porvir do cosmopolitismo por vir a propósito das cidades-refúgio, re-inventar a cidadania (II). Revista Filosófica de Coimbra, Coimbra, v. 11, n. 22, p. 421-446, 2002.

BRAIDOTTI, R. Lo posthumano. Barcelona: Gedisa, 2015.

BRAIDOTTI, R. Nomadic Theory. New York: Columbia University Press, 2011.

CASPAR, B. Angesichts des Anderen. Emmanuel Levinas, Elemente seines Denkens. Paderborn: Ferdinand Schöningh, 2009.

CHRÉTIEN, J.-L. L'appel et la réponse. Paris: PUF, 1992.

DERRIDA, J. L'écriture et la différence. Paris: Seuil, 1967.

DERRIDA, J. De l'hospitalité. Paris: Calmann-Lévy, 1997.

DERRIDA, J. Donner la mort. Paris: Galilée, 1999.

DUQUE, J. M. Deus (im)possível. Sobre Teologia e Filosofia na Pós-modernidade. In: XAVIER, M. L. L. O. (Ed.). A questão de Deus na História da Filosofia. Lisboa: Zéfiro, 2008. 1295-1303.

DUQUE, J. M. Hospitalidade e violência. Sobre um possível fundamento religioso anterior ao estado laico, Franciscanum, Bogotá, v. 59, n. 167, p. 195-213, jan./jun., 2017.

FORNARI-CARBONELL, I. M. La escucha del huésped (Lc 10, 38-42): La hospitalidad en el horizonte de la comunicación. Estella: Verbo Divino, 1995.

FOUNTOULAKIS, E.; Previsic, B. (orgs.). Der Gast als Fremder. Narrative Alterität in der Literatur. Bielefeld: Transcript Verlag, 2011.

GIRARD, R. La violence et le Sacré. Paris: Grasset, 1972.

GIRARD, R. Le bouc emissaire. Paris: Grasset, 1982.

GIRARD, R. Des choses cachées depuis la fondation du monde. Paris: Grasset, 2001.

GISEL, P. L'excès de croire, Paris: Desclée de Brouwer, 1990.

LEVINAS, E. Autrement qu'être et au-dela de l'essence. Paris: Grasset, 1974.

LEVINAS, E. Du Sacréau Saint. Cinq nouvelles lectures talmudiques. Paris: Minuit, 1977.

LEVINAS, E. Dieu, la mort et le temps. Paris: Grasset, 1993. 
LEVINAS, E. Totalité et Infini. La Haye: Martinus Nijhoff, 1971.

LEVINAS, E. L'humanisme de l'autre homme. Paris: Fata Morgana, 1972.

MARION, J.-L. Étant donné. Essai d'une phénoménologie de la donnation. Paris: PUF, 1997.

PATOCKA, J. Essais hérétiques sur la philosophie de l'histoire. Paris: Verdier, 1999.

RICOEUR, P. Amour et justice: Liebe und Gerechtigkeit. Tübingen: J. C. B. Mohr, 1990.

RICOEUR, P. J. Patocka et le nihilisme. Ricoeur, P. Lectures 1. Paris: Seuil, 1991.

RICOEUR, P. A Religião e a violência. Revista Portuguesa de Filosofia, Braga, v. 56, n. 1-2, p. 25-35, jan./jun., 2000.

ROSA, H. Unverfügbarkeit. Wien: Residenz Verlag, 2019.

SOUSA CORREIA, J. A. A hospitalidade na construção da identidade cristã. Lisboa: UC Editora, 2014.

SPLETT, J. Denken vor Gott. Frankfurt a. M.: Knecht, 1996.

THEOBALD, C. Le christianisme comme style. v. 1, Paris: Cerf, 2007.

THEOB ALD, C. Pour une aproche stylistique du croire chrétien. Scripta Fulgentina, Múrcia, v. 22, n. 43-44, p. 43-59, 2012.

ZAGALO, G. Hospitalidade e soberania - uma leitura de Jacques Derrida. Revista Filosófica de Coimbra, Coimbra, v. 15, n. 30, p. 307-323, 2006.

Artigo submetido em 11.08.2020 e aprovado em 01.12.2020.

João Manuel Duque é Doutor em Teologia pela Philosophisch-Theologische Hochschule Sankt Georgen, Frankfurt (1996) e Professor Catedrático na Universidade Católica Portuguesa, Pesquisador Integrado do Centro de Investigação em Teologia e Estudos de Religião da Universidade Católica Portuguesa. Orcid.org/0000-0002-9252-6709. E-mail: jmduque@sapo.pt

Endereço: Universidade Católica Portuguesa

Campus Camões,

Rua Camões, s/n

4710-362 Braga - Portugal 